\title{
Acaricidal activity of Cinnamomum cassia (Chinese cinnamon) against the tick Haemaphysalis longicornis is linked to its content of $(E)$-cinnamaldehyde
}

\author{
Chuks F. Nwanade ${ }^{1}$, Min Wang ${ }^{1}$, Tianhong Wang ${ }^{2}$, Xiaoyu Zhang ${ }^{1}$, Can Wang ${ }^{1}$, Zhijun Yu ${ }^{1 *}$ and Jingze Liu ${ }^{1 *}$
}

\begin{abstract}
Background: The tick Haemaphysalis longicornis (Neumann) is a well-known vector of numerous pathogens of veterinary and medical importance. Various control strategies, including the use of synthetic pesticides, have been developed to control this tick species. However, demand for effective and safe alternative pesticides is increasing due to the adverse effects associated with the intensive and injudicious use of synthetic pesticides, which include undesirable effects on non-target species and environmental pollution. Hence, the acaricidal activity of the extract and the essential oil of Cinnamomum cassia (Chinese cinnamon) and their major components, and the underlying mechanisms of this activity, were evaluated against unfed larvae and nymphs of H. longicornis.
\end{abstract}

Methods: The components of the extract and essential oil of C. cassia were determined by gas chromatographymass spectrometry, and their larvicidal and nymphicidal activity were evaluated using the larval and nymphal packet test. The underlying detoxification mechanism was elucidated by targeting in vivo esterase and monooxygenase activity, and the toxicological effect was assessed on non-target Tenebrio molitor and Harmonia axyridis by topical application in open Petri dishes.

Results: (E)-cinnamaldehyde was the predominant component of the extract (50.79\%) and essential oil (89.95\%). The $50 \%$ lethal concentration $\left(\mathrm{LC}_{50}\right)$ for larvae and nymphs treated with the extract was 11.56 and $49.18 \mathrm{mg} / \mathrm{mL}$, respectively. The essential oil, (E)-cinnamaldehyde and fenvalerate exhibited acaricidal activity, with $\mathrm{LC}_{50}$ values of 3.81, 3.15, and $0.14 \mathrm{mg} / \mathrm{mL}$, respectively, against the larvae, and $21.31,16.93$, and $1.89 \mathrm{mg} / \mathrm{mL}$, respectively, against the nymphs. (E)-cinnamaldehyde significantly increased esterase and monooxygenase activity in both larvae and nymphs. Unlike fenvalerate, C. cassia essential oil and (E)-cinnamaldehyde did not cause mortality of T. molitor or H. axyridis adults.

Conclusions: This study demonstrates that $C$. cassia essential oil and $(E)$-cinnamaldehyde have the potential to be developed into botanical-based larvicidal and nymphicidal agents for tick control.

Keywords: Cinnamomum cassia, Extract, Essential oil, (E)-cinnamaldehyde, Haemaphysalis longicornis, Non-target organism

\footnotetext{
${ }^{*}$ Correspondence: yuzhijun@hebtu.edu.cn; liujingze@hebtu.edu.cn ${ }^{1}$ Hebei Key Laboratory of Animal Physiology, Biochemistry

and Molecular Biology, College of Life Sciences, Hebei Normal University, Shijiazhuang 050024, China

Full list of author information is available at the end of the article
}

\section{Background}

The long-horned tick Haemaphysalis longicornis Neumann (Acari: Ixodidae) is an obligate hematophagous ectoparasite native to East Asian countries, and was recently found to be established in several states of the

(c) The Author(s) 2021. This article is licensed under a Creative Commons Attribution 4.0 International License, which permits use, sharing, adaptation, distribution and reproduction in any medium or format, as long as you give appropriate credit to the original author(s) and the source, provide a link to the Creative Commons licence, and indicate if changes were made. The images or other third party material in this article are included in the article's Creative Commons licence, unless indicated otherwise in a credit line to the material. If material is not included in the article's Creative Commons licence and your intended use is not permitted by statutory regulation or exceeds the permitted use, you will need to obtain permission directly from the copyright holder. To view a copy of this licence, visit http://creativeco mmons.org/licenses/by/4.0/. The Creative Commons Public Domain Dedication waiver (http://creativecommons.org/publicdomain/ zero/1.0/) applies to the data made available in this article, unless otherwise stated in a credit line to the data. 
USA [1]. In recent years, control of this tick has attracted much attention because of its ability to acquire and transmit numerous zoonotic pathogens, including severe fever with thrombocytopenia syndrome virus $[2,3]$. In addition, it is a major pest of livestock in Australia and New Zealand, and infestation, which can cause exsanguination, can lead to economic losses related to reduced growth and production [4]. Various control strategies, including the use of synthetic pesticides, have been developed to control tick species including H. longicornis [5]. However, the demand for effective and safe alternative pesticides is increasing due to the adverse effects, including environmental pollution and undesirable effects on non-target species, associated with the intensive and injudicious use of synthetic pesticides [6]. Plant-based products including essential oils and extracts provide good alternatives because they are effective against a wide variety of pests and have little or no toxicity against non-target species [7, 8]. Cinnamomum (Lauraceae) is among the plant genera with promising insecticidal activity [9]. This genus is composed of about 250 species, including the economically important Cinnamomum cassia Presl [10].

C. cassia is an evergreen aromatic plant species native to tropical and subtropical regions including China [11]. It is an important material in Chinese traditional medicine for the treatment of various ailments such as dysmenorrhea and menoxenia [11]. C. cassia also has numerous pharmacological properties that are of great importance to the food and pharmaceutical industries. For example, $C$. cassia essential oil has been demonstrated to be an effective natural antibacterial agent against Shiga toxin-producing Escherichia coli, an important foodborne pathogen [12]. Another potential industrial application of $C$. cassia is as an antioxidant agent because of its radical scavenging ability [13]. C. cassia has several other important pharmacological properties, including anticholesterol and antidiabetes activities [14]. Despite its medicinal uses and potential for use in industry, its potential for application in tick management has scarcely been examined.

In the present study, the extract and essential oil of $C$. cassia bark, and their major component, $(E)$-cinnamaldehyde, which were characterized by gas chromatography-mass spectrometry, and the (synthetic) pyrethroid, fenvalerate, were evaluated in vitro against unfed larvae and nymphs of $H$. longicornis. The larvae and nymphs are important immature stages of $H$. longicornis as they have been implicated as vectors of tick-borne pathogens, including Rickettsia rickettsii, the agent of Rocky Mountain spotted fever [15]. Therefore, they are considered strategic targets in tick control programs [16, 17]. Furthermore, to elucidate their possible detoxification mechanisms, the effects of the essential oil and $(E)$-cinnamaldehyde [with low $50 \%$ lethal concentration $\left(\mathrm{LC}_{50}\right)$ values in the in vitro test] on the biochemical parameters of larvae and nymphs of $H$. longicornis were tested by targeting in vivo esterase and monooxygenase activity. In ticks, esterase and monooxygenase are common detoxification enzymes against xenobiotic compounds [18]. Finally, to evaluate their environmental safety, the toxicological effects of the essential oil and $(E)$-cinnamaldehyde were evaluated on the following non-target terrestrial invertebrates: Tenebrio molitor (Coleoptera: Tenebrionidae), a beneficial insect of ecological and nutritional importance [19, 20]; and Harmonia axyridis (Coleoptera: Coccinellidae), a biocontrol agent of aphids, scales and other phytophagous pests [21].

\section{Methods}

\section{Preparation of extracts and source of essential oil}

The bark of C. cassia was obtained commercially in September 2019 , from Yulin, Guangxi, China $\left(22.625248^{\circ} \mathrm{N}\right.$, $110.18473^{\circ} \mathrm{E}$ ), and identified in the Herbarium of College of Life Sciences, Hebei Normal University, Shijiazhuang, China, from voucher specimen 20,006,001. The dried and pulverized bark of C. cassia was macerated with $100 \%$ methanol, as described by Rawa et al. [22]. The supernatants were collected using a Buchner funnel. The resulting filtrates were dried under reduced pressure at $40{ }^{\circ} \mathrm{C}$ using a vacuum rotary evaporator. Extracts were stored at $4{ }^{\circ} \mathrm{C}$ in an airtight brown bottle until tested for acaricidal activity. C. cassia bark essential oil [Generally Regarded as Safe for human consumption (US Food and Drug Administration)] was obtained from a local supplier (Yu Cheng product workshop) in Chaozhou, Guangdong, China. This supplier extracts essential oils on a small scale by hydrodistillation.

\section{Determination of the components of $C$. cassia extract and essential oil}

Components of C. cassia extract and essential oil were determined on a gas chromatography-mass spectrometer (model 7890A-5975C; Agilent Technologies, USA). Chromatographic separation was achieved using a DB5 MS capillary column $(30 \mathrm{~m} \times 0.25 \mathrm{~mm} \times 0.25 \mu \mathrm{m})$. The carrier gas was helium at $1 \mathrm{~mL} / \mathrm{min}$ flow rate, and the spilt ratio 10:1. The temperature conditions were $60{ }^{\circ} \mathrm{C}$ for $2 \mathrm{~min}$, increased to $150{ }^{\circ} \mathrm{C}$ for $1 \mathrm{~min}$, and finally to $280{ }^{\circ} \mathrm{C}$ for $5 \mathrm{~min}$. The mass spectrometer was bombarded with an electron impact ionization source, and the electron energy was $70 \mathrm{eV}$. The inlet temperature was $280{ }^{\circ} \mathrm{C}$ and the ion source temperature was $230{ }^{\circ} \mathrm{C}$. The mass scanning range was $40-550 \mathrm{~m} / \mathrm{z}$. Compounds were identified using the Standard Reference Database of the National Institute of Standards and Technology. 


\section{Chemicals}

Analytical grade methanol was purchased from Baishi Chemicals (Tianjin, China). (E)-cinnamaldehyde (98\%; lot no. I1918074), a clear yellow liquid, was purchased from Aladdin Biochemical (Shanghai, China). Fenvalerate (Hubei Danongren Biological Technology), used as a sample synthetic (commercial) acaricide, was purchased from a local market. Esterase, monooxygenase, and protein assay kits were purchased from Shanghai Enzymelinked Biotechnology (Shanghai, China).

\section{Test organisms}

Unfed adult ticks of $H$. longicornis were collected from vegetation by tick dragging at Xiaowutai National Nature Reserve Area $\left(40^{\circ} 03^{\prime} 03^{\prime \prime} \mathrm{N}, 115^{\circ} 23^{\prime} 15^{\prime \prime} \mathrm{E}\right)$, Zhangjiakou, Hebei Province, China. Unfed adult ticks were placed on the ears of New Zealand white rabbits and the resulting engorged females were maintained in an incubator $\left[26 \pm 1{ }^{\circ} \mathrm{C}, 85 \pm 5 \%\right.$ relative humidity $(\mathrm{RH}), 16: 8 \mathrm{~h}$ (light:dark; L:D) photoperiod] for oviposition. The larvae that hatched during a period of 14 days and the nymphs that molted during a period of 14 days were used for subsequent tests.

T. molitor larvae were collected from a commercial breeder in Zhengzhou, Henan, China. They were first reared to the pupal and then to the adult stage on a diet of wheat bran and potato slices in plastic containers $(18 \times 11 \times 11 \mathrm{~cm})$, as described by George et al. [19], under laboratory conditions $\left[25 \pm 1{ }^{\circ} \mathrm{C}, 70 \pm 5 \% \mathrm{RH}\right.$, 16:8-h photoperiod (L:D)]. Adults 6-10 days after eclosion, and larvae (>15 mm), were used in this study [23]. $H$. axyridis larvae were commercially obtained (Jiangsu, China), and reared according to Benelli et al. [8]. Larvae were fed aphids ad libitum and maintained in an incubator $\left[25 \pm 1{ }^{\circ} \mathrm{C}, 70 \pm 5 \% \mathrm{RH}, 16: 8\right.$-h photoperiod (L:D)], and the resulting adults (3-7 days old) were used in this study.

\section{Acaricidal activity}

Acaricidal activity against the larvae and nymphs of $H$. longicornis was determined using larval and nymphal packet tests. First, the bark extract of $C$. cassia, essential oil of $C$. cassia, and $(E)$-cinnamaldehyde were diluted with $70 \%$ methanol. There is little or no toxicity of $70 \%$ methanol when it is used as a solvent in the packet test in vitro (filter papers soaked with the test compounds were allowed to dry before use in a closed packet containing ticks) [see details of the larval packet test (LPT) below]. In addition, previous studies have shown that analytical grade methanol (undiluted) has little or no toxicity against tick species, and it has been suggested as a suitable solvent for dissolving plant extracts when testing acaricidal activity [24]. Then a range finding test was carried out to determine the appropriate test concentrations. For larvae, five concentrations were used, ranging from 5.00 to $20.00 \mathrm{mg} / \mathrm{mL}$ for the extract, $2.75-$ $5.00 \mathrm{mg} / \mathrm{mL}$ for the essential oil, $2.75-3.70 \mathrm{mg} / \mathrm{mL}$ for (E)-cinnamaldehyde, and $0.025-0.750 \mathrm{mg} / \mathrm{mL}$ for fenvalerate. For nymphs, five to six concentrations were used, ranging from 40.00 to $60.00 \mathrm{mg} / \mathrm{mL}$ for the extract, $10.00-30.00 \mathrm{mg} / \mathrm{mL}$ for the essential oil, $5.00-30.00 \mathrm{mg} /$ $\mathrm{mL}$ for $(E)$-cinnamaldehyde, and $0.38-4.50 \mathrm{mg} / \mathrm{mL}$ for fenvalerate.

The LPT was carried out according to the in vitro test recommended by the Food and Agriculture Organization of the United Nations [25], as described by Godara et al. [26]. Briefly, filter papers $(7.5 \times 9.0 \mathrm{~cm}$, Whatman No. 1 ; Whatman, Maidstone, UK) were soaked with $1 \mathrm{~mL}$ of the dilutions. The treated filter papers were allowed to dry and were then folded into packets and sealed on the side with clips. One hundred larvae were introduced into each packet before sealing the top of with clips. The packets containing the larvae were kept in an incubator $\left(26 \pm 1{ }^{\circ} \mathrm{C}\right.$ and $85 \pm 5 \% \mathrm{RH})$. After $24 \mathrm{~h}$, the packets were examined for larval mortality. Distilled water and 70\% methanol served as the negative control group, and fenvalerate diluted with distilled water, as specified on the product label, served as the positive control. Each treatment and control group was replicated four times. A similar LPT was used for unfed nymphs, with ten nymphs placed into each packet; each treatment and the negative control group (distilled water and $70 \%$ methanol) and positive control group (fenvalerate) was replicated five times.

\section{Effect $\left(\mathrm{LC}_{50}\right)$ on non-target $T$. molitor}

The essential oil and $(E)$-cinnamaldehyde of $C$. cassia were selected due to their low $\mathrm{LC}_{50}$ values against unfed larvae and nymphs of $H$. longicornis (Figs. 1, 2). Adults of $T$. molitor were exposed to $\mathrm{LC}_{50}$ of $C$. cassia essential oil $(3.81$ and $21.31 \mathrm{mg} / \mathrm{mL}$, respectively, for larvae and nymphs of $H$. longicornis) and $(E)$-cinnamaldehyde (3.15 and $16.93 \mathrm{mg} / \mathrm{mL}$, respectively) (Figs. 1, 2) using the method described by Pedersen et al. [23]. Exposure was performed by topical application in open Petri dishes (diameter, $9 \mathrm{~cm}$ ). Briefly, the abdomen was held with a soft tweezer, causing the beetle to lower its head, which exposed the soft part between the pronotum and elytra. Each adult received a $1-\mu \mathrm{L}$ droplet of the test solutions using a micropipette (Eppendorf, Hamburg, Germany). Likewise, larvae received a $1-\mu \mathrm{L}$ droplet of the test solutions in the area that was proportionally equal in proximity to the head. Adults and larvae of T. molitor exposed to $\mathrm{LC}_{50}$ of fenvalerate $(0.14$ and $1.89 \mathrm{mg} / \mathrm{mL}$, respectively, for larvae and nymphs of $H$. longicornis), as estimated in the toxicity bioassay, were used as a positive 

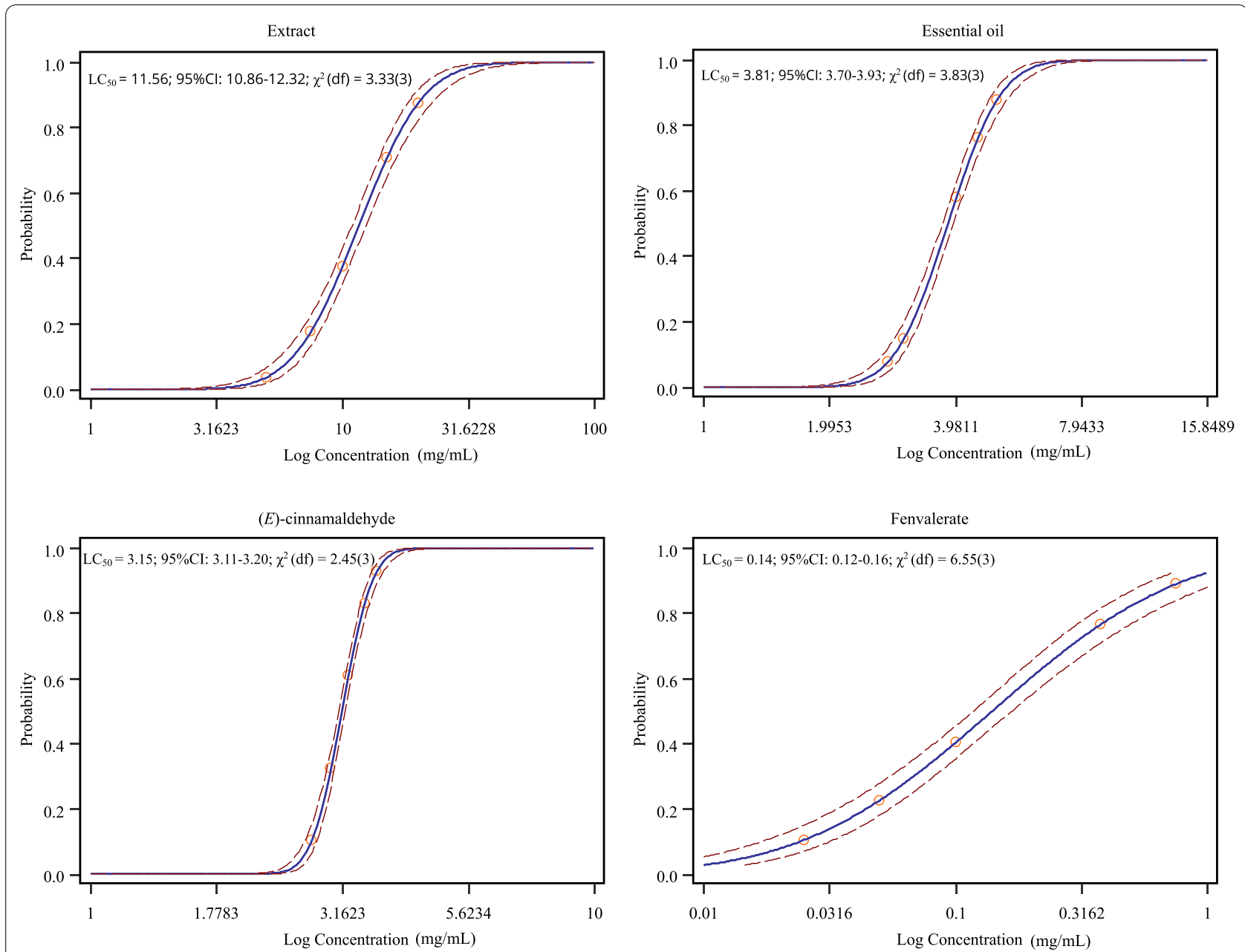

Fig. 1 Concentration-response curves of Haemaphysalis longicornis larvae. Solid lines represent the estimated mean. Dotted lines represent 95\% confidence intervals ( $C l$; lower and upper) around the mean. $L C_{50}$ Lethal concentration required to kill $50 \%$ of the population at $24 \mathrm{~h}$

control. Negative control groups included adults and larvae exposed to $70 \%$ methanol and distilled water. Treated adults and larvae were transferred to clean Petri dishes (ten beetles per dish), and fed with wheat bran and potato slices. All dishes were maintained in the incubator $\left[25 \pm 1{ }^{\circ} \mathrm{C}, 70 \pm 5 \% \mathrm{RH}, 16: 8\right.$-h photoperiod (L:D)]. The numbers of dead larvae and adults of T. molitor were determined $48 \mathrm{~h}$ after treatment. T. molitor that did not respond to the probe were considered dead. Each treatment and control group was replicated five times.

\section{Effect $\left(\mathrm{LC}_{50}\right)$ on non-target $H$. axyridis}

The effects of the $\mathrm{LC}_{50}$ for larvae and nymphs of $\mathrm{H}$. longicornis of C. cassia essential oil (3.81 and $21.31 \mathrm{mg} /$ $\mathrm{mL}$, respectively) and $(E)$-cinnamaldehyde (3.15 and $16.93 \mathrm{mg} / \mathrm{mL}$, respectively) on adult $H$. axyridis were assessed by using a minor modification of the method described by Youn et al. [27]. In the present study, $1 \mu \mathrm{L}$ of the test solutions was topically applied to adults at the junction between the pronotum and elytron using a micropipette (Eppendorf). Adults of $H$. axyridis exposed to $\mathrm{LC}_{50}$ of fenvalerate for larvae and nymphs of $\mathrm{H}$. longicornis $(0.14$ and $1.89 \mathrm{mg} / \mathrm{mL})$ were used as positive controls. Negative control groups included adults exposed to $70 \%$ methanol and distilled water. Treated adults were transferred to clean Petri dishes (ten adults per dish), fed with Metopolophium dirhodum, and maintained in an incubator $\left[25 \pm 1{ }^{\circ} \mathrm{C}, 70 \pm 5 \% \mathrm{RH}, 16: 8\right.$-h photoperiod (L:D)]. The number of dead $H$. axyridis was determined $48 \mathrm{~h}$ after treatment [7], with adults that did not respond to a probe considered dead. Each treatment and the control groups were replicated five times.

\section{Biochemical analysis}

The in vivo enzyme activities were measured for unfed larvae and nymphs of $H$. longicornis exposed to $\mathrm{LC}_{50}$ 

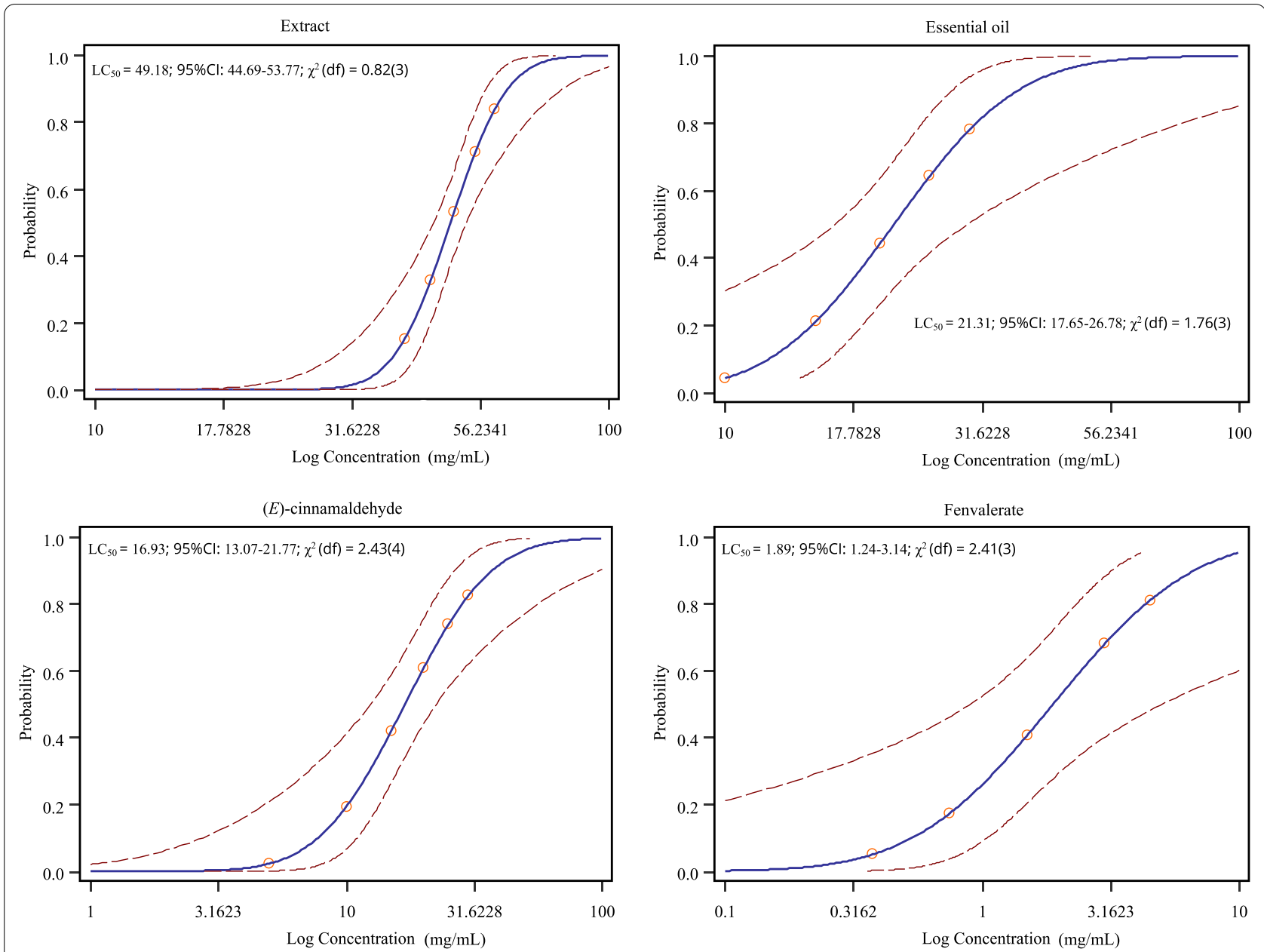

Fig. 2 Concentration-response curves of $\mathrm{H}$. longicornis nymphs. Solid lines represent the estimated mean. Dotted lines represent $95 \% \mathrm{Cl}$ around the mean. For abbreviations, see Fig. 1

of the essential oil (3.81 and $21.31 \mathrm{mg} / \mathrm{mL}$, respectively) and $(E)$-cinnamaldehyde $(3.15$ and $16.93 \mathrm{mg} / \mathrm{mL}$, respectively) (Figs. 1, 2). Larvae and nymphs exposed to $\mathrm{LC}_{50}$ of fenvalerate $(0.14$ and $1.89 \mathrm{mg} / \mathrm{mL}$, respectively) (Figs. 1,2) were used as a positive control. Negative control groups included larvae and nymphs exposed to $70 \%$ methanol and distilled water. The essential oil and $(E)$-cinnamaldehyde were selected due to their low $\mathrm{LC}_{50}$ values against unfed larvae and nymphs of $H$. longicornis (Figs. 1, 2). About $20 \mathrm{mg}$ of the larvae and nymphs that survived after treatments in the packet assays was homogenized in $400 \mu \mathrm{L}$ pre-cooled phosphate-buffered solution $(0.1 \mathrm{M}, \mathrm{pH} 7.2)$. The homogenate was centrifuged at $3000 \times g$ at $4{ }^{\circ} \mathrm{C}$ for $10 \mathrm{~min}$. The resulting supernatant was removed and used for esterase and monooxygenase assays using the corresponding ELISA kit (Shanghai Enzyme-linked Biotechnology), and for the protein assay using bicinchoninic acid protein assay kit (Shanghai Enzyme-linked Biotechnology), following the manufacturer's instructions. For each tested concentration and control group, there were three replicates.

\section{Statistical analyses}

Statistical analyses were performed using SPSS software (v20.0; IBM, Armonk, NY). The normality of residuals was first verified using the Shapiro-Wilk test. Then, ANOVA and Tukey's test were used to determine the significance of the data of the biochemical analyses. Kruskal-Wallis and Student-Newman-Keuls post hoc test were used to determine the significance of the percentage mortality of the non-target species. Mortality of $H$. longicornis larvae in the negative control (70\% methanol only) was below $5 \%$, thus no correction of mortality was necessary [25]. $\mathrm{LC}_{50}$ were determined by performing a probit analysis on the tick mortality data [28] using SPSS (v20.0) and MedCalc (v19.6.4; MedCalc, Ostend, Belgium) software. 


\section{Results and discussion}

\section{Chemical composition}

In the C. cassia extract, a total of 14 compounds representing $97.39 \%$ of the total extract were identified. The major constituent of this extract was $(E)$-cinnamaldehyde (50.79\%). The percentage compositions of the remaining 13 compounds ranged from 0.97 to $15.83 \%$ (Table 1 ). In C. cassia essential oil, 16 compounds were identified, accounting for $97.11 \%$ of the total composition. Specifically, the major constituent was $(E)$-cinnamaldehyde (89.95\%). The percentage abundance of the remaining 15 compounds ranged from 0.13 to $1.68 \%$ (Table 1 ).

The presence of $(E)$-cinnamaldehyde as the predominant component in the extract and essential oil from $C$. cassia bark in the present study is in accordance with results reported in other studies $[29,30]$. However, the chemical composition of the extract and essential oil from $C$. cassia bark is affected by many factors including methods of extraction, and the different agroecological conditions during the growth and development of the plant [30]. As a result, several species of C. cassia have been reported with different percent contents of $(E)$-cinnamaldehyde [29, 30]. For example, in the study of Deng et al. [29], (E)-cinnamaldehyde was the predominant component and accounted for about $72.23 \%$ of C. cassia bark essential oil. In a recent study, Liang et al. [30] found that $(E)$-cinnamaldehyde $(62.96 \%)$ was a major component of $C$. cassia bark extract. In addition, in other species of Cinnamomum, (E)-cinnamaldehyde is also a major component, and accounted for about $66.43 \%$ of
Cinnamomum zeylanicum bark essential oil [31]. In the present study, the percent content of $(E)$-cinnamaldehyde in the essential oil (89.95\%) was higher than in the extract $(50.79 \%)$. A possible explanation for variation in the percent content of $(E)$-cinnamaldehyde may be the different methods used for the extraction of the extract and essential oil. Variation in the percent content of $(E)$-cinnamaldehyde can also be due to the geographical origin of the C. cassia and the method used for the extraction of the extract and essential oil [30].

\section{Acaricidal activity, effect $\left(\mathrm{LC}_{50}\right)$ on non-target species, and biochemical activity}

The acaricidal activity was evaluated by the packet test for unfed larvae and nymphs of $H$. longicornis. After treatment of unfed larvae and nymphs of $H$. longicornis for $24 \mathrm{~h}$, C. cassia essential oil, with $\mathrm{LC}_{50}$ values of 3.81 and $21.31 \mathrm{mg} / \mathrm{mL}$, respectively, and $(E)$-cinnamaldehyde, with $\mathrm{LC}_{50}$ values of 3.15 and $16.93 \mathrm{mg} / \mathrm{mL}$, respectively, exhibited greater acaricidal activity compared with $C$. cassia extract, with $\mathrm{LC}_{50}$ values of 11.56 and $49.18 \mathrm{mg} / \mathrm{mL}$, respectively (Figs. 1, 2). However, the efficacy of the essential oil and $(E)$-cinnamaldehyde was lower compared with that of fenvalerate (synthetic acaricide), with $\mathrm{LC}_{50}$ values of 0.14 and $1.89 \mathrm{mg} / \mathrm{mL}$ against the larvae and nymphs, respectively (Figs. 1, $2)$. Despite these results, $C$. cassia essential oil and $(E)$ cinnamaldehyde can be considered as potential candidates for the development of larvicidal and nymphicidal agents for tick control. This conclusion is justified

Table 1 The compounds obtained from the bark extract and essential oil of Cinnamomum cassia

\begin{tabular}{|c|c|c|c|c|c|c|}
\hline \multirow[t]{2}{*}{$\mathrm{S} / \mathrm{N}$} & \multirow[t]{2}{*}{ Retention time } & \multirow[t]{2}{*}{ Area \% } & \multicolumn{2}{|l|}{ Compounds } & \multirow[t]{2}{*}{ Area \% } & \multirow[t]{2}{*}{ Retention time } \\
\hline & & & Extract & Essential oil & & \\
\hline 1 & 6.748 & 11.99 & 3-Methoxy-3-phenylpropanal & Tetrahydro-2-furanol & 0.42 & 3.230 \\
\hline 2 & 6.951 & 50.79 & (E)-cinnamaldehyde & Butyrolactone & 0.16 & 4.999 \\
\hline 3 & 7.582 & 2.83 & Copaene & 2-Furanmethanol & 1.39 & 5.124 \\
\hline 4 & 8.016 & 1.78 & Cinnamyl acetate & Benzaldehyde & 0.26 & 5.688 \\
\hline 5 & 8.183 & 15.83 & (E)-2-hydroxycinnamic acid & (Z)-cinnamaldehyde & 0.52 & 8.240 \\
\hline 6 & 8.431 & 2.53 & a-Muurolene & (E)-cinnamaldehyde & 89.95 & 8.809 \\
\hline 7 & 8.559 & 3.16 & $\beta$-Cadinene & Copaene & 0.18 & 9.433 \\
\hline 8 & 8.601 & 1.21 & Cis-calamenene & Trans-cinnamic acid & 1.09 & 9.777 \\
\hline 9 & 8.642 & 1.83 & 2-Methoxycinnamaldehyde & Cinnamyl ester & 0.40 & 9.842 \\
\hline 10 & 8.671 & 0.97 & Cubenene & Coumarin & 0.33 & 9.919 \\
\hline 11 & 9.399 & 1.14 & Syringaldehyde & y-Muurolene & 0.15 & 10.092 \\
\hline 12 & 9.399 & 1.14 & T-muurolol & Cadina-1(10),4-diene & 0.13 & 10.353 \\
\hline 13 & 11.013 & 1.03 & Palmitic acid & 2-Methoxycinnamaldehyde & 1.68 & 10.430 \\
\hline 14 & 11.876 & 1.16 & Linoleic acid & Benzene & 0.18 & 10.55 \\
\hline 15 & & & & 2-Methyl-1-naphthalenol & 0.14 & 10.727 \\
\hline 16 & & & & 1-Phenyl-hexa-1,5-dione & 0.13 & 11.071 \\
\hline
\end{tabular}


from a toxicological and a mechanistic perspective. For instance, from a toxicological point of view, it is important not only to assess the efficacy of new plantbased pesticides on target species but also to estimate any effect on non-target species [7]. Herein, we evaluated the effect of $C$. cassia essential oil and $(E)$-cinnamaldehyde on the mortality of non-target species, i.e. T. molitor and H. axyridis. T. molitor is presently being promoted as a beneficial insect, as it is capable of degrading polystyrene and plastic waste, and may play an important role in litter decomposition [19, 20]. In addition, T. molitor larvae are often used as pet food, and offer a promising alternative protein source for human and animal nutrition [20]. Besides this, predatory behavior of $T$. molitor on ticks has been reported [32]. H. axyridis is a biocontrol agent of pests including aphids, scales, and other phytophagous pests, and plays an important role in regulating the populations of these pests [21]. Topical application of the essential oil (tested concentration: $\mathrm{LC}_{50} 3.81$ and $21.31 \mathrm{mg} /$ $\mathrm{mL}$ for unfed larvae and nymphs of $H$. longicornis) or (E)-cinnamaldehyde (tested concentration: LC $_{50} 3.15$ and $16.93 \mathrm{mg} / \mathrm{mL}$, respectively) did not cause mortality in T. molitor or Harmonia axyridis adults (Fig. 3A, $\mathrm{B})$, which may indicate that these compounds are environmentally safe. Generally, essential oils and their active compound(s) are not toxic to non-target organisms $[7,8]$, in accordance with our results. For example, essential oil from Stevia rebaudiana did not cause any significant mortality in $H$. axyridis larvae or adults, and had no adverse effect on Eisenia fetida earthworm adults [8].

However, topical application of fenvalerate (tested concentration: $\mathrm{LC}_{50} 1.89 \mathrm{mg} / \mathrm{mL}$ for the nymphs of $H$. longicornis) resulted in significant mortality in adult $T$. molitor $\left[18.00 \pm 7.35 ; F_{(4,20)}=15.444, p=0.000\right]$ and $H$. axyridis $\left[8.00 \pm 3.74 ; F_{(4,20)}=5.952, p=0.003\right]$ when compared with the control (Fig. $3 \mathrm{~A}, \mathrm{~B}$ ), which indicates that fenvalerate may inhibit their performance as beneficial organisms and biocontrol agents. Furthermore, there was no mortality in the larvae of $T$. molitor treated with fenvalerate (tested concentrations: $\mathrm{LC}_{50} 0.14$ and $\mathrm{LC}_{50}$ $1.89 \mathrm{mg} / \mathrm{mL}$, for larvae and nymphs of $H$. longicornis) during the 48-h observation period, thus these data were omitted from all calculations and comparisons. Pedersen et al. [23] found that T. molitor adults were more sensitive to exposure to the pyrethroid $\alpha$-cypermethrin than their larvae. It is possible that the size of an insect and its structure may affect the amount of a chemical that enters its body [8, 23]. Generally, synthetic insecticides including pyrethroids have a negative effect on non-target species $[7,8]$. For example, treatment with $\alpha$-cypermethrin at $1.6 \times 10^{-6} \mathrm{~mL} / \mathrm{L}$ caused about $50 \%$ mortality in nontarget $H$. axyridis adults [8].

It is important to note that the results of the non-target assay should be interpreted with caution, given the different experimental designs, including the non-uniform methods (LPT verse topical application) used to assess

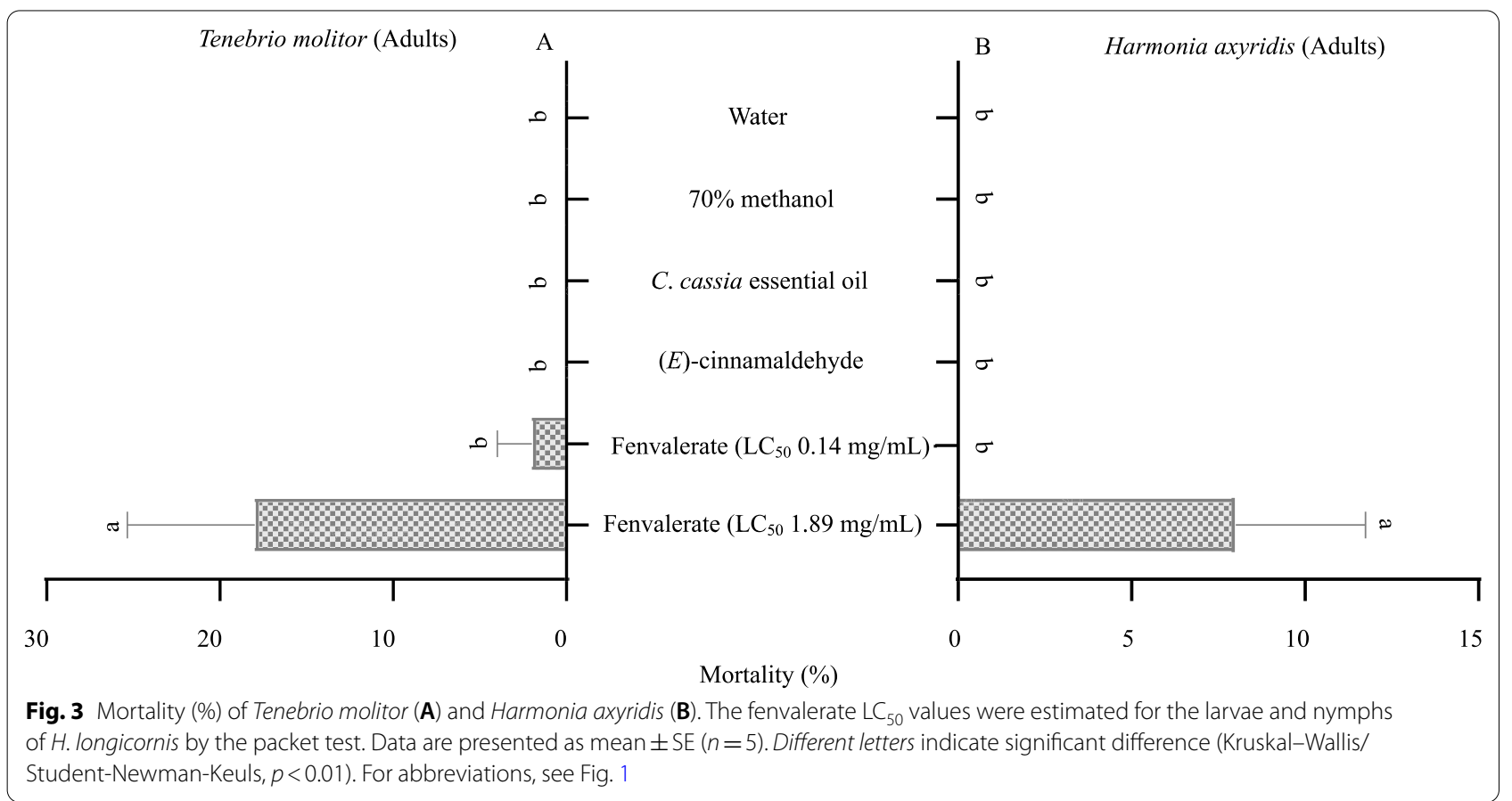


toxicity on the target and non-target species, which may have caused Haemaphysalis longicornis, T. molitor and Harmonia axyridis to react differently to the test substances. Moreover, the toxicity of a substance usually depends on the amount acquired by the test organism $[8,23]$. Thus, the lack of toxicity of C. cassia essential oil and $(E)$-cinnamaldehyde in non-target $T$. molitor and $H$. axyridis could have been due to their exposure to lower concentrations than the ticks, as a result of the different in vitro assays used. However, our observations in this study are significant in that they provide an indication of the potential effects of $C$. cassia essential oil and $(E)$-cinnamaldehyde on non-target $T$. molitor and $H$. axyridis, and provide the basis for the design of future studies which will take into account, among other factors, the disparities between the experimental designs used in this present study.

Elucidating the underlying detoxification mechanism can provide important clues for the development of botanical-based acaricides. In the present study, both the essential oil of C. cassia and (E)-cinnamaldehyde significantly affected the activities of detoxification enzymes in ticks, including those of esterase and monooxygenase. For example, in contrast to the fenvalerate treatment, esterase activity was significantly increased in larvae [Fig. 4A; $F_{(4,10)}=17.549, p=0.000$ ] and nymphs of $H$. longicornis [Fig. 4B; $F_{(4,10)}=39.363, p=0.000$ ] exposed to $(E)$-cinnamaldehyde (tested concentration: $\mathrm{LC}_{50} 3.15$ and $16.93 \mathrm{mg} / \mathrm{mL}$, respectively) when compared with the control. Likewise, esterase activity significantly increased when the nymphs were exposed to $C$. cassia essential oil (tested concentration: $\mathrm{LC}_{50} 21.31 \mathrm{mg} / \mathrm{mL}$ ) (Fig. 4B). On the other hand, similar to the effects of fenvalerate, monooxygenase activity was significantly increased in the larvae [Fig. 4C; $F_{(4,10)}=22.346, p=0.000$ ] and nymphs [Fig. 4D; $F_{(4,10)}=33.181, p=0.000$ ] after treatment with $\mathrm{LC}_{50}$ of $C$. cassia essential oil and $(E)$-cinnamaldehyde. Esterase and monooxygenase are involved in the metabolic detoxification of pesticides [33]. In ticks, they play an important role in the development of resistance to synthetic acaricides [18, 34]. For example, resistance to synthetic pyrethroids was found to be significantly correlated with increase esterase and monooxygenase activities in Rhipicephalus microplus [34]. It has also been demonstrated that the inhibition of detoxification enzymes, including esterase, led to an increase in the mortality of a resistant strain of $R$. microplus [35]. The increased expression of esterase and monooxygenase in the present study may indicate their involvement in the detoxification response against $C$. cassia essential oil and (E)-cinnamaldehyde. However, additional studies are needed to test different times of exposure, since esterase and monooxygenase activities may decrease with time
[33], and to explore the contribution of other metabolic enzymes such as acetylcholinesterase and glutathione S-transferases to defense mechanisms. It is important to note that the total protein content of $H$. longicornis after treatment with $C$. cassia essential oil, $(E)$-cinnamaldehyde and fenvalerate ranged from 0.98 to $1.05 \mathrm{mg} / \mathrm{mL}$ for the larvae and $0.96-1.13 \mathrm{mg} / \mathrm{mL}$ for the nymphs, and treatment with the essential oil, $(E)$-cinnamaldehyde and fenvalerate did not induce significant changes in the total protein of either.

In addition, based on the present results, the efficacy of $C$. cassia essential oil in terms of $\mathrm{LC}_{50}$ values, i.e. lower concentrations compared with those of the extract (Figs. 1, 2), may be attributed to the high percent content of the main component, $(E)$-cinnamaldehyde. $(E)$ cinnamaldehyde is the key component of $C$. cassia bark responsible for its insecticidal and acaricidal activity [36]. When tested as a pure compound, $(E)$-cinnamaldehyde was effective against the larvae and nymphs of Rhipicephalus sanguineus, with $100 \%$ mortality at 2.55 and $10 \mu \mathrm{L} /$ $\mathrm{mL}$, respectively [37]. A similar observation was recorded for the larvae of Amblyomma cajennense at a (E)-cinnamaldehyde concentration of $5.0 \mu \mathrm{L} / \mathrm{mL}$ [37]. Likewise, (E)-cinnamaldehyde was effective with $100 \%$ mortality at a concentration of $5 \mu \mathrm{L} / \mathrm{mL}$ against $R$. microplus and Dermacentor nitens larvae [38]. Acaricidal activity of $(E)$ cinnamaldehyde was also observed against the larvae of Amblyomma sculptum ( $\mathrm{LC}_{50} 1.40 \mathrm{mg} / \mathrm{mL}$ ) and $D$. nitens $\left(\mathrm{LC}_{50} 1.68 \mathrm{mg} / \mathrm{mL}\right)$ [39]. Besides its efficacy against ticks, (E)-cinnamaldehyde was found to be an efficient mosquito larvicidal against Aedes albopictus, Culex quinquefasciatus and Armigeres subalbatus, with $\mathrm{LC}_{50}$ values below $50 \mu \mathrm{g} / \mathrm{mL}$ [40].

Compared with other essential oils, for example, essential oil of Cymbopogon citratus $\left(\mathrm{LC}_{50}\right.$ values of 28.06 and $28.18 \mathrm{mg} / \mathrm{mL}$ for larvae and nymphs of $H$. longicornis, respectively) [41], C. cassia bark essential oil tested in this study showed greater acaricidal activity against the larvae and nymphs of $H$. longicornis. The insecticidal activity of $C$. cassia essential oil has also been reported for other target species, e.g. against the nymphs of Ricania sp., with an $\mathrm{LC}_{50}$ value of $37.66 \mathrm{mg} /$ $\mathrm{mL}$ after exposure for $72 \mathrm{~h}$ [42]. In addition, the insecticidal activity of $C$. cassia extract has been reported for pests of stored products including Tribolium castaneum and Lasioderma serricorne, with $\mathrm{LD}_{50}$ values of 3.96 and $23.89 \mu \mathrm{g} /$ adult, respectively [43]. To our knowledge, the present study is the first report on the acaricidal activity of $C$. cassia extract and essential oil against vector ticks. The essential oils obtained from other species of Cinnamomum have also been studied against tick species. For example, the larvicidal activity of Cinnamomum zeylanicum essential oil was evaluated 

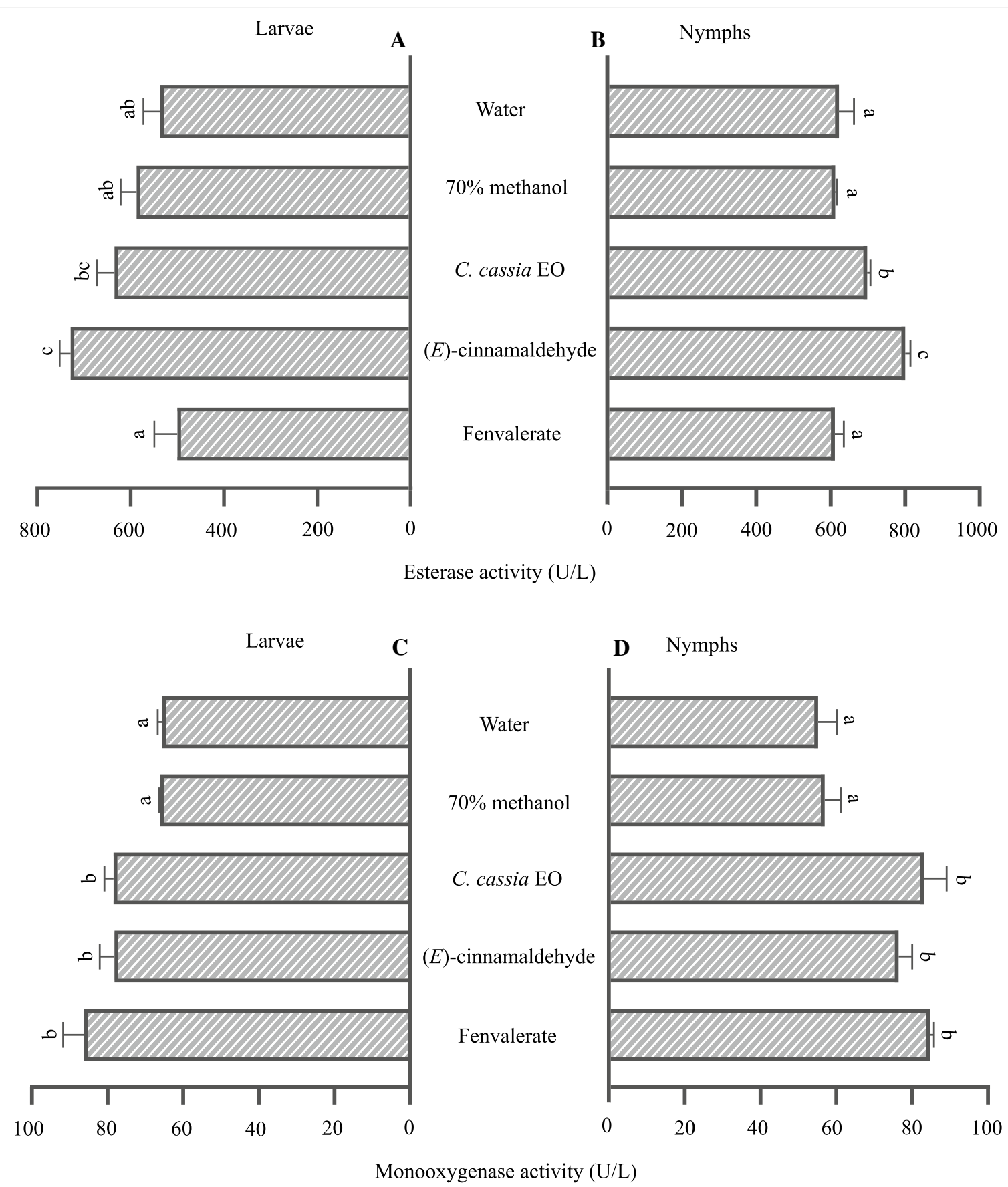

Fig. 4 A-D Esterase and monooxygenase activities of larvae and nymphs of H. longicornis. Data are presented as the mean $\pm S E(n=3)$. Different letters indicate a significant difference (Tukey's test, $p<0.001$ ). EO Essential oil

against $R$. microplus larvae, with an $\mathrm{LC}_{50}$ of $0.086 \%$ [44]. Apart from acaricidal activity, Cinnamomum verum essential oil was found to exhibit larvicidal activity against fourth-instar Cx. quinquefasciatus $\left(\mathrm{LC}_{50} 40.7\right.$ $\mu \mathrm{L} / \mathrm{L}$ ) and adulticidal ( $\mathrm{LC}_{50} 42 \mu \mathrm{g} /$ adult) activity against Musca domestica [9].
Cinnamon oil is considered safe by the US Food and Drug Administration and is exempted from toxicity data requirements by the US Environmental Protection Agency [36, 42]. However, there are potential safety concerns regarding cinnamaldehyde. For example, cinnamaldehyde at certain exposure concentrations reduces 
adenosine triphosphate levels and disrupts mitochondrial function in human bronchial epithelial cells [45]. Thus, during in vivo and/or field trials of C. cassia products, concentration-response curves should be determined. These can be used to identify lethal and non-lethal concentrations for ticks and mammalian hosts. Additionally, application of C. cassia products directly to the host may provide better protection from tick infestation, since hosts can be kept in enclosures to protect them against environmental factors including weather conditions that could interfere with the efficacy of the applied products [46]. Natural product-based acaricides are sensitive to environmental factors, thus, they do not persist for long in the environment [47].

\section{Conclusions}

The C. cassia products tested in the present study, especially the essential oil and $(E)$-cinnamaldehyde, exhibited good acaricidal activity against larvae and nymphs of Haemaphysalis longicornis, whereas no toxic effect was found against the terrestrial invertebrates $T$. molitor and Harmonia axyridis, which suggests that they may not be harmful to non-target terrestrial invertebrates when used as acaricides. The defense response of the larvae and nymphs of $H$. longicornis to C. cassia essential oil and $(E)$ cinnamaldehyde may be partly related to the increased synthesis of esterase and monooxygenase. In addition, the acaricidal activity of $C$. cassia essential oil or extract is likely related to the biochemical activity of $(E)$-cinnamaldehyde, i.e. the increased expression of esterase and monooxygenase activity. However, the molecular mechanism underlying the acaricidal activity of $C$. cassia warrants further exploration, and future studies on its effects on other non-target species such as soil-dwelling (earthworms) and aquatic organisms are imperative.

\section{Acknowledgements}

Chuks F. Nwanade acknowledges support from the China Scholarship Council. The authors would like to thank Dr. Abolfazl Masoudi for his technical input.

\section{Authors' contributions}

CFN, ZY, and JL designed the project. ZY identified the tick species. CFN and CW performed the plant extractions. CFN, MW, and XZ performed the bioassay. CFN and TW wrote the draft manuscript. ZY and JL critically revised the manuscript. All authors read and approved the final manuscript.

\section{Funding}

This work was supported by the National Natural Science Foundation of China (32070494, 32071510), the Youth Top Talent Support Program of Hebei Province to ZY, the Natural Science Foundation of Hebei Province (C2019205064), Financial Assistance for the Introduction of Overseas Researchers (C20190350), the High-level Talent Support Project of Hebei Province (A201901031) and the Science Foundation of Hebei Normal University (L2018J04).

\section{Availability of data and materials}

The data used and analyzed during the current study are available from the corresponding author on reasonable request.

\section{Declarations}

\section{Animal welfare statement}

The experimental protocols in this study fully complied with the animal protection law of the People's Republic of China, and were approved by the Animal Ethics Committee of Hebei Normal University (protocol no. 157031).

\section{Competing interests}

The authors declare no conflict of interest.

\section{Author details}

${ }^{1}$ Hebei Key Laboratory of Animal Physiology, Biochemistry and Molecular Biology, College of Life Sciences, Hebei Normal University, Shijiazhuang 050024,

China. ${ }^{2}$ Department of Biochemistry and Biology, Basic Medical College, Hebei University of Chinese Medicine, Shijiazhuang 050200, China.

Received: 16 March 2021 Accepted: 7 June 2021

Published online: 22 June 2021

References

1. Pritt BS. Haemaphysalis longicornis is in the United States and biting humans: where do we go from here? Clin Infect Dis. 2020;70:317-8.

2. Luo LM, Zhao L, Wen HL, Zhang ZT, Liu JW, Fang LZ, et al. Haemaphysalis longicornis ticks as reservoir and vector of severe fever with thrombocytopenia syndrome virus in China. Emerg Infect Dis. 2015;21:1770-6.

3. Yu ZJ, Wang H, Wang TH, Sun WY, Yang XL, Liu JZ. Tick-borne pathogens and the vector potential of ticks in China. Parasites Vectors. 2015;8:24.

4. Heath ACG. Biology, ecology and distribution of the tick, Haemaphysalis longicornis Neumann (Acari: Ixodidae) in New Zealand. N Z Vet J. 2016:64:10-20.

5. Park G, Kim HK, Lee W, Cho S, Kim G. Evaluation of the acaricidal activity of 63 commercialized pesticides against Haemaphysalis longicornis (Acari: Ixodidae). Entomol Res. 2019:49:330-6.

6. Pisa LW, Amaral-Rogers V, Belzunces LP, Bonmatin JM, Downs CA, Goulson $D$, et al. Effects of neonicotinoids and fipronil on non-target invertebrates. Environ Sci Pollut Res. 2015;22:68-102.

7. Pavela R. Essential oils from Foeniculum vulgare Miller as a safe environmental insecticide against the aphid Myzus persicae Sulzer. Environ Sci Pollut Res. 2018;25:10904-10.

8. Benelli G, Pavela R, Drenaggi E, Desneux N, Maggi F. Phytol, (E)-nerolidol and spathulenol from Stevia rebaudiana leaf essential oil as effective and eco-friendly botanical insecticides against Metopolophium dirhodum. Ind Crops Prod. 2020;155:112844.

9. Benelli G, Pavela R, Giordani C, Casettari L, Curzi G, Cappellacci L, et al. Acute and sub-lethal toxicity of eight essential oils of commercial interest against the filariasis mosquito Culex quinquefasciatus and the housefly Musca domestica. Ind Crops Prod. 2018;112:668-80.

10. Sriramavaratharajan V, Sudha V, Murugan R. Characterization of the leaf essential oils of an endemic species Cinnamomum perrottetii from Western Ghats. India Nat Prod Res. 2015:30:1085-7.

11. Zhang C, Fan L, Fan S, Wang J, Luo T, Tang Y, et al. Cinnamomum cassia Presl: a review of its traditional uses, phytochemistry, pharmacology and toxicology. Molecules. 2019;24:3473.

12. Sheng LN, Zhu MJ. Inhibitory effect of Cinnamomum cassia oil on non-0157 Shiga toxin-producing Escherichia coli. Food Control. 2014;46:374-81.

13. Yang CH, Li RX, Chuang LY. Antioxidant activity of various parts of Cinnamomum cassia extracted with different extraction methods. Molecules. 2012;17:7294-304.

14. Hamidpour R, Hamidpour M, Hamidpour S, Shahlari M. Cinnamon from the selection of traditional applications to its novel effects on the inhibition of angiogenesis in cancer cells and prevention of Alzheimer's disease, and a series of functions such as antioxidant, anticholesterol, antidiabetes, antibacterial, antifungal, nematicidal, acaracidal, and repellent activities. J Tradit Complement Med. 2015;5:66-70.

15. Stanley HM, Ford SL, Snellgrove AN, Hartzer K, Smith EB, Krapiunaya I, et al. The ability of the invasive Asian longhorned tick Haemaphysalis longicornis (Acari: Ixodidae) to acquire and transmit Rickettsia rickettsii 
(Rickettsiales: Rickettsiaceae), the agent of Rocky Mountain spotted fever, under laboratory conditions. J Med Entomol. 2020;57:1635-9.

16. Adenubi OT, McGaw LJ, Eloff JN, Naidoo V. In vitro bioassays used in evaluating plant extracts for tick repellent and acaricidal properties: a critical review. Vet Parasitol. 2018;254:160-71.

17. Ferreira FM, Delmonte CC, Novato T, Monteiro C, Daemon E, Vilela F, et al. Acaricidal activity of essential oil of Syzygium aromaticum, hydrolate and eugenol formulated or free on larvae and engorged females of Rhipicephalus microplus. Med Vet Entomol. 2018;32:41-7.

18. Gaudêncio FN, Klafke GM, Tunholi-Alves VM, Ferreira TP, Coelho CN, da Fonseca AH, et al. Activity of carboxylesterases, glutathione-S-transferase and monooxygenase on Rhipicephalus microplus exposed to fluazuron. Parasitol Int. 2017;66:584-7.

19. George DR, Sparagano OA, Port G, Okello E, Shiel RS, Guy JH. Repellence of plant essential oils to Dermanyssus gallinae and toxicity to the nontarget invertebrate Tenebrio molitor. Vet Parasitol. 2009;162:129-34.

20. Vigneron A, Jehan C, Rigaud T, Moret Y. Immune defenses of a beneficial pest: the mealworm beetle Tenebrio molitor. Front Physiol. 2019;10:138.

21. Omkar PA. Ecology and biological control application of multicoloured Asian ladybird, Harmonia axyridis: a review. Biocontrol Sci Technol. 2006;16:111-28.

22. Rawa MSA, Hassan Z, Murugaiyah V, Nogawa T, Wahab HA. Anti-cholinesterase potential of diverse botanical families from Malaysia: evaluation of crude extracts and fractions from liquid-liquid extraction and acid-base fractionation. J Ethnopharmacol. 2019;245:112160.

23. Pedersen KE, Pedersen NN, Meyling NV, Fredensborg BL, Cedergreen N. Differences in life stage sensitivity of the beetle Tenebrio molitor towards a pyrethroid insecticide explained by stage-specific variations in uptake, elimination and activity of detoxifying enzymes. Pestic Biochem Phys. 2020;162:113-21.

24. Ravindran R, Juliet S, Kumar KG, Sunil AR, Nair SN, Amithamol KK, et al. Toxic effects of various solvents against Rhipicephalus (Boophilus) annulatus. Ticks Tick-Borne Dis. 2011;2:160-2.

25. Food and Agriculture Organization of the United Nations. Module 1. Ticks: acaricides resistance: diagnosis management and prevention. In: Guidelines resistance management and integrated parasite control in ruminants. Rome: FAO Animal Production and Health Division; 2004. p. 25-77.

26. Godara R, Parveen S, Katoch R, Yadav A, Verma PK, Katoch M, et al. Acaricidal activity of extract of Artemisia absinthium against Rhipicephalus sanguineus of dogs. Parasitol Res. 2014;113:747-54.

27. Youn YN, Seo MJ, Shin JG, Jang C, Yu YM. Toxicity of greenhouse pesticides to multicolored Asian lady beetles, Harmonia axyridis (Coleoptera: Coccinellidae). Biol Control. 2003:28:164-70.

28. Finney DJ. Probit analysis. London: Cambridge University Press; 1971.

29. Deng X, Liao Q, Xu X, Yao M, Zhou Y, Lin M, et al. Analysis of essential oils from cassia bark and cassia twig samples by GC-MS combined with multivariate data analysis. Food Anal Methods. 2014;7:1840-7.

30. Liang Y, LiY, Sun A, Liu X. Chemical compound identification and antibacterial activity evaluation of cinnamon extracts obtained by subcritical n-butane and ethanol extraction. Food Sci Nutr. 2019;7:2186-93.

31. Tran HNH, Graham L, Adukwu EC. In vitro antifungal activity of Cinnamomum zeylanicum bark and leaf essential oils against Candida albicans and Candida auris. Appl Microbiol Biotechnol. 2020;104:8911-24.

32. Samish M, Alekseev E. Arthropods as predators of ticks (Ixodoidea). J Med Entomol. 2001;38:1-11.

33. Huang Y, Lin M, Jia M, Hu J, Zhu L. Chemical composition and larvicidal activity against Aedes mosquitoes of essential oils from Arisaema fargesii. Pest Manage Sci. 2020;76:534-42.
34. Fular A, Gupta S, Sharma AK, Kumar S, Upadhaya D, Shakya M, et al. Standardization of tick specific biochemical tools for estimation of esterases, monooxygenases and glutathione $S$-transferase for characterization of acaricide resistance. Pestic Biochem Phys. 2020;164:130-9.

35. Le Gall VL, Klafke GM, Torres TT. Detoxification mechanisms involved in ivermectin resistance in the cattle tick, Rhipicephalus (Boophilus) microplus. Sci Rep. 2018:8:12401.

36. Kang MS, Lee HS. Acaricidal and insecticidal responses of Cinnamomum cassia oils and main constituents. Appl Biol Chem. 2018;61:653-9.

37. Senra TOS, Calmon F, Zeringóta V, Monteiro CMO, Maturano R, da Silva $M R$, et al. Investigation of activity of monoterpenes and phenylpropanoids against immature stages of Amblyomma cajennense and Rhipicephalus sanguineus (Acari: Ixodidae). Parasitol Res. 2013;112:3471-6.

38. Senra TOS, Zeringóta V, Monteiro CMO, Calmon F, Maturano R, Gomes $\mathrm{GA}$, et al. Assessment of the acaricidal activity of carvacrol, (E)-cinnamaldehyde, trans-anethole, and linalool on larvae of Rhipicephalus microplus and Dermacentor nitens (Acari: Ixodidae). Parasitol Res. 2013;112:1461-6.

39. Novato TP, Araújo LX, de Monteiro CM, Maturano R, Senra T, da Silva $M R$, et al. Evaluation of the combined effect of thymol, carvacrol and (E)-cinnamaldehyde on Amblyomma sculptum (Acari: Ixodidae) and Dermacentor nitens (Acari: Ixodidae) larvae. Vet Parasitol. 2015;212:331-5.

40. Cheng SS, Liu JY, Huang CG, Hsui YR, Chen WJ, Chang ST. Insecticidal activities of leaf essential oils from Cinnamomum osmophloeum against three mosquito species. Bioresour Technol. 2009;100:457-64.

41. Agwunobi DO, Pei T, Wang K, Yu ZJ, Liu JZ. Effects of the essential oil from Cymbopogon citratus on mortality and morphology of the tick Haemaphysalis longicornis (Acari: Ixodidae). Exp Appl Acarol. 2020;81:37-50.

42. Jeon YJ, Lee SG, Yang YC, Lee HS. Insecticidal activities of their components derived from the essential oils of Cinnamomum sp. barks and against Ricania sp. (Homoptera: Ricaniidae), a newly recorded pest. Pest Manage Sci. 2017;73:2000-4.

43. Wang Y, Dai P, Guo S, Cao J, Pang X, Geng Z, et al. Supercritical carbon dioxide extract of Cinnamomum cassia bark: toxicity and repellency against two stored-product beetle species. Environ Sci Pollut Res. 2018;25:22236-43.

44. Singh NK, Singh H, Mehta N, Rath SS. In vitro assessment of synergistic combinations of essential oils against Rhipicephalus (Boophilus) microplus Canestrini (Acari: Ixodidae). Exp Parasitol. 2019;201:42-8.

45. Clapp PW, Lavrich KS, van Heusden CA, Lazarowski ER, Carson JL, Jaspers I. Cinnamaldehyde in flavored e-cigarette liquids temporarily suppresses bronchial epithelial cell ciliary motility by dysregulation of mitochondrial function. Am J Physiol Lung Cell Mol Physiol. 2019;316:470-86.

46. Corrêa RR, Lopes WD, Teixeira WF, Cruz BC, Gomes LV, Felippelli G, et al. A comparison of three different methodologies for evaluating RhipicephaIus (Boophilus) microplus susceptibility to topical spray compounds. Vet Parasitol. 2015;207:1 15-24.

47. Eisen L, Dolan MC. Evidence for personal protective measures to reduce human contact with blacklegged ticks and for environmentally based control methods to suppress host-seeking blacklegged ticks and reduce infection with Lyme disease spirochetes in tick vectors and rodent reservoirs. J Med Entomol. 2016;53:1063-92.

\section{Publisher's Note}

Springer Nature remains neutral with regard to jurisdictional claims in published maps and institutional affiliations. 